\title{
A single-nucleotide polymorphism in the RAD5 I gene modifies breast cancer risk in BRCA2 carriers, but not in BRCAI carriers or noncarriers
}

\author{
L Kadouri,', Z Kote-Jarai ${ }^{2}$, A Hubert', F Durocher ${ }^{3}$, D Abeliovich ${ }^{4}$, B Glaser ${ }^{5}$, T Hamburger', \\ RA Eeles ${ }^{2,6,7}$ and T Peretz ${ }^{1,7}$
}

'Sharett Institute of Oncology, Hebrew University-Hadassah Medical Center, Jerusalem, Israel; ${ }^{2}$ Cancer Research UK Section of Cancer Genetics, The Institute of Cancer Research, Sutton, UK; ${ }^{3}$ Cancer Genomics Laboratory, CHUL Research Center, Faculty of Medicine, Laval University, Quebec, Canada; ${ }^{4}$ Human Genetic Laboratories, Hebrew University-Hadassah Medical Center, Jerusalem, Israel; ${ }^{5}$ Department of Endocrinology and Metabolism, Hebrew University-Hadassah Medical Center, Jerusalem, Israel; ${ }^{6}$ The Royal Marsden NHS Trust, Sutton, UK

Variation in the penetrance estimates for BRCAI and BRCA2 mutation carriers suggests that other genetic polymorphisms may modify the cancer risk in carriers. The RAD5 I gene, which participates in homologous recombination double-strand breaks (DSB) repair in the same pathway as the BRCAI and BRCA2 gene products, is a candidate for such an effect. A single-nucleotide polymorphism (SNP), RAD5 I-I35g $\rightarrow \mathrm{C}$, in the $5^{\prime}$ untranslated region of the gene has been found to elevate breast cancer (BC) risk among BRCA2 carriers. We genotyped 309 BRCA //2 mutation carriers, of which 280 were of Ashkenazi origin, 166 noncarrier BC patients and 152 women unaffected with BC (a control group), for the RAD5 I I I35g $\rightarrow$ c SNP. Risk analyses were conducted using COX proportional hazard models for the BRCA //2 carriers and simple logistic regression analysis for the noncarrier case-control population. BRCA2 carriers were also studied using logistic regression and Kaplan-Meier survival analyses. The estimated BC hazard ratio (HR) for RAD5 I - I 35c carriers adjusted for origin (Ashkenazi vs non-Ashkenazi) was 1.28 (95\% Cl 0.85-1.90, $P=0.23$ ) for BRCA / /2 carriers, and $2.09(95 \% \mathrm{Cl} 1.04-4.18, P=0.04)$ when the analysis was restricted to BRCA2 carriers. The median BC age was younger in BCRA2-RAD5 I - I 35c carriers ( 45 ( $95 \% \mathrm{Cl} 36-54)$ vs 52 years ( $95 \% \mathrm{Cl} 48-56), P=0.05$ ). In a logistic regression analysis, the odds ratio $(O R)$ was $5.49(95 \% \mathrm{Cl} 0.5-58.8, P=0.163)$. In noncarrier $B C$ cases, carrying $R A D 5$ I -135 c was not associated with $B C$ risk $(0.97 ; 95 \% \mathrm{Cl} 0.47-2.00)$. These results indicate significantly elevated risk for $\mathrm{BC}$ in carriers of BRCA2 mutations who also carry a RAD5 I- I35c allele. In BRCAI carriers and noncarriers, no effect for this SNP was found.

British Journal of Cancer (2004) 90, 2002-2005. doi:I 0. I 038/sj.bjc.660I837 www.bjcancer.com

Published online 27 April 2004

(c) 2004 Cancer Research UK

Keywords: BRCAI/2; BC risk; RAD5I gene; single-nucleotide polymorphism

Carriers of a mutated $B R C A 1$ or $B R C A 2$ gene are at an increased risk of breast $(\mathrm{BC})$ and ovarian cancer $(\mathrm{OC})$; however, penetrance estimates differ in various study populations (Easton et al, 1995; Struewing et al, 1997; Ford et al, 1998; Thorlacius et al, 1998). Modification of the risk by other genes or environmental factors clustering in families probably explains most of this difference. Genes involved in DNA repair, especially those that interact with the product of the $B R C A 1$ or $B R C A 2$ genes, are of particular interest as cancer risk modifiers in $B R C A 1 / 2$ mutation carriers.

Both BRCA1 and BRCA2 participate in DNA double-strand break repair through homologous recombination (reviewed in Venkitaraman, 2002). RAD51, a eukaryotic homologue of the bacterial RecA protein, is essential for DSB repair. The three molecules co-localise in mitotic and meiotic cells and in DNA foci

\footnotetext{
* Correspondence: Dr L Kadouri, Sharett Institute of Oncology, Hadassah Medical Center, Jerusalem 9| I20, Israel; E-mail: luna@hadassah.org.ll 7 Joint last authors

Received 2 September 2003; revised 4 March 2004; accepted I I March 2004; published online 27 April 2004
}

induced by irradiation. Phenotypic similarities of brca1-, brca2and rad51-deficient murine models, as well as gross chromosomal rearrangements such as translocations and deletions, which are a common feature of brca1/2 or rad51 null cells, suggest that they function in a common pathway.

A single-nucleotide polymorphism (SNP), $g \rightarrow c$, at position 135 of the untranslated region of the RAD51 gene has been reported (Levy-Lahad et al, 2001; Wang et al, 2001). The biological effect of this polymorphism is currently unknown. However, in two studies, an elevated BC risk associated with the RAD51-135c allele was reported in BRCA2 mutation carriers, but not in BRCA1 mutation carriers (Levy-Lahad et al, 2001; Wang et al, 2001). A lower risk for OC in BRCA2 carriers was also suggested by the larger study (Wang et al, 2001). Recently, an opposite effect of reduced BC risk was reported in a population of BRCA1-5382insC carriers who also carry the RAD51-135c (Jakubowska et al, 2003). This polymorphism was not associated with BC risk in a large case-control study in noncarrier population (Kuschel et al, 2002).

In order to confirm these results, we assessed the effect of the $R A D 51-135 \mathrm{~g} \rightarrow \mathrm{c}$ polymorphism on $\mathrm{BC}$ risk in BRCA1/2 mutation carriers and in noncarrier $\mathrm{BC}$ cases, mainly of Ashkenazi origin. 


\section{SUBJECTS AND METHODS}

\section{Study population}

Two populations were studied: (1) BRCA1/2 mutation carriers of Ashkenazi and non-Ashkenazi origin and (2) noncarrier, BC patients and a control group without cancer, of Ashkenazi origin. Blood samples from 309 BRCA1/2 mutation carriers were collected through two centres: 263 carriers were identified through the oncology department and the cancer genetics clinic in the Hadassah Medical Center in Jerusalem, Israel, and 46 through the cancer genetics clinic at the Royal Marsden NHS Trust, London, UK. Cases were tested on the basis of a family history of breast and/or OC or on the basis of their Ashkenazi origin. All but one of the cases from Jerusalem were carriers of one of the three Ashkenazi founder mutations (145 cases: 185delAG in BRCA1, 35 cases: 5382 insC in $B R C A 1$ and 82 cases: 6174 delT in BRCA2). The UK carriers included 17 carriers of Ashkenazi founder mutations (one individual carried both a 185delAG and 6174delT) and 29 other mutations (22 in BRCA1; 7 in BRCA2). Of the 309 carriers, 177 were affected with BC, 40 with OC and 17 had both cancers. In all, 69 of the mutation carriers were unaffected. Clinical data were unavailable for six of the carriers.

A total of 166 'noncarrier' Ashkenazi Jewish BC patients were ascertained through the oncology department in Hadassah over the period of 1994-98. They were enrolled according to the same protocol as the $B R C A 1 / 2$ carriers, but were found to be negative for carrying any of the three Ashkenazi founder BRCA1/2 mutations. In all, $24(14 \%)$ of the patients were diagnosed below age 40 years, $54(33 \%)$ were aged $40-49$ years and $88(53 \%)$ were aged $50+$ years. Where data were available (111 noncarrier cases), 71 (64\%) reported a positive family history of BC. Thus, this series has a higher frequency of early-onset cases and cases with a family history than would be expected in the Ashkenazi population overall.

The controls were 152 females who took part in an independent study into the genetics of diabetes. All controls were cancer-free, of Ashkenazi origin and aged above 56 years (mean age 69, range 56-92 years). All participants signed an informed consent approved by the local institutional ethics committee or gave permission for samples to be used in an anonymous way for research purposes.

\section{Genotyping}

Genomic DNA was extracted according to standard protocols, and used as a template for the PCR reaction. An SNP of $\mathrm{g} \rightarrow \mathrm{c}$ at position 135 in the untranslated region of the RAD51 gene was analysed using two methods: the ABI/PE Biosystems Taqman system and a standard PCR and digestion technique. Eight samples including three positive for the RAD51-135c allele were genotyped using both methods, the results were $100 \%$ concordant. By the ABI/PE Biosystems Taqman method, PCR amplification was carried out in a final volume of $25 \mu$ l containing $25 \mathrm{ng}$ genomic DNA, $900 \mathrm{~nm}$ of each primer, $200 \mathrm{~nm}$ FAM-labelled probe, $200 \mathrm{~nm}$ VIC-labelled probe and $12.5 \mu \mathrm{l} 2 \times$ Universal PCR master mix (PE Biosystems) containing optimised buffer components and Rox reference dye. The primer sequences were as follows: forward $5^{\prime}$ gca gcc tcc tct ctc cag c- $3^{\prime}$; reverse $5^{\prime}$-gct ggg aac tgc aac tca tct- $3^{\prime}$. Probe sequences were $5^{\prime}$-Fam-ccc caa cgc ccc tgg ctt ac $-3^{\prime}$ and $5^{\prime}-$ Vic-caa cgc ccg tgg ctt acg ct- $3^{\prime}$. The PCR amplification cycles were $95^{\circ} \mathrm{C}$ for $10 \mathrm{~min}$, followed by 40 cycles of $95^{\circ} \mathrm{C}$ for $15 \mathrm{~s}$ and $62^{\circ} \mathrm{C}$ for $1 \mathrm{~min}$. Levels of FAM and TET fluorescence were determined and allelic discrimination was done using the ABI 7700 Sequence detector. By PCR and digestion (Levy-Lahad et al, 2001; Wang et al, 2001), a PCR product of $157 \mathrm{bp}$ containing the $R A D 51-135 \mathrm{~g} \rightarrow \mathrm{c}$ polymorphism was amplified using the primers, forward: $5^{\prime}$ tgggaactgcaactcatctgg- $3^{\prime}$ and reverse: $5^{\prime}$-gcgctcctctctccagcag- 3 , in a mixture containing $1.5 \mathrm{mM} \mathrm{MgCl}_{2}$ at an annealing temperature of $53^{\circ} \mathrm{C}$. The wild-type allele is digested by $M v a \mathrm{I}$, resulting in $86-$ and 71-bp products. This restriction site is missing in the polymorphic c allele. The PCR products were separated on a $3.0 \%$ agarose gel with $2 \mu \mathrm{l}(100 \mathrm{ml})^{-1}$ of ethidiume bromide.

\section{Statistical analysis}

The effects of RAD51 genotypes on BC risk in mutation carriers were evaluated using a COX proportional hazards model. Participants were followed up retrospectively from the date of birth to several possible outcomes. The outcome in women affected with $\mathrm{BC}$ was recorded as the age at first $\mathrm{BC}$ diagnosis. Women unaffected with BC were censored at the date of OC diagnosis, prophylactic surgery, date of last follow-up, or death. Since the distributions of age and disease status, and potentially the genotype distribution, were different in the Ashkenazi and non-Ashkenazi populations, the analyses were adjusted for ethnic origin. Although selection of participants is partly based on outcome, this method of analysis was used previously for risk estimation in carriers (Rebbeck et al, 1999; Levy-Lahad et al, 2001). In our study (Kadouri et al, 2001) on the modifying effect of the androgen receptor in $B R C A$ carriers, we compared COX proportional hazards models to a variant of the log rank designed to overcome selection bias by comparison of outcome to expected penetrance according to the literature. Since the estimated risks were close in both methods, in the current paper we have used COX proportional hazard models. The significant analysis by COX proportional hazard models (association in BRCA2 carriers) was also analysed using logistic regression analysis and Kaplan-Meier survival analysis, the event was recorded as first BC diagnosis and unaffected women were censored in the same way as for the COX analysis.

Clinical data were not available for six individuals, and six individuals could not be genotyped, so that in the final analysis 297 mutation carriers were included, 191 BC cases and 39 OC cases (including one woman diagnosed simultaneously with both cancers and therefore counted as affected with both cancers) and 67 unaffected carriers.

The case-control analyses based on the non-carrier BC cases $(n=155)$ and controls $(n=142)$ were performed using a standard logistic regression approach. All analyses were performed using SPSS.

\section{RESULTS}

The RAD51-135c heterozygote frequency was 41 out of 303 (13.5\%) in all $B R C A 1 / 2$ carriers, 35 out of $276(12.7 \%)$ in the Ashkenazi carrier population and six out of $27(22.2 \%)$ in the British (nonAshkenazi) population (Table 1). No RAD51-135c homozygotes

Table I Frequencies of RAD5 $1-135 \mathrm{~g} / \mathrm{c}$ alleles by disease status in BRCAI/2 mutation carriers

\begin{tabular}{lccc}
\hline Clinical presentation & $\begin{array}{c}\text { All }^{\mathbf{a}} \\
(\mathbf{n}=\mathbf{2 9 7})\end{array}$ & $\begin{array}{c}\text { BRCAI } \\
(\mathbf{n}=\mathbf{2 1 0})\end{array}$ & $\begin{array}{c}\text { BRCA2 } \\
(\mathbf{n}=\mathbf{8 6})\end{array}$ \\
\hline Breast cancer & $22 / 124(17.2 \%)$ & $13 / 78(16.2 \%)$ & $9 / 46(19.6)$ \\
Bilateral breast cancer & $3 / 50(6 \%)$ & $3 / 43(7 \%)$ & $0 / 7(0 \%)$ \\
Breast and ovarian cancer & $2 / 17^{\mathrm{b}}(11.7 \%)$ & $1 / 12^{\mathrm{c}}(8.3 \%)$ & $1 / 5^{\mathrm{d}}(20 \%)$ \\
Ovarian cancer & $6 / 39(11.7 \%)$ & $6 / 27(22.2 \%)$ & $0 / 12(0 \%)$ \\
Unaffected & $8 / 67(11.9 \%)$ & $7 / 50(14 \%)$ & $1 / 16(6.25 \%)$ \\
\hline
\end{tabular}

Including one carrier of both |85delAG\&6|74delT mutations. bIncluding three individuals with bilateral BC and OC, of which one has RAD5 I-135c. Including two individuals with bilateral BC and OC, of which one has RAD5 I-135c. Including one individual with bilateral $\mathrm{BC}$ and $\mathrm{OC}$. 
Table 2 Frequencies of RAD5 I- $135 \mathrm{~g} \rightarrow \mathrm{c}$ alleles by $\mathrm{BC}$ disease status and $\mathrm{BC}$ relative risk $(\mathrm{RR})$ in $\mathrm{BRCAI} / 2$ carriers and noncarriers

\begin{tabular}{|c|c|c|c|c|c|}
\hline Genotype & BC $-{ }^{a}(n=106)$ no. $(\%)$ & $B C++^{b}(n=191)$ no. $(\%)$ & Av. age at BC onset (year) ${ }^{c}$ & Breast cancer HR $(95 \% \mathrm{Cl})$ & $P$-value \\
\hline Rad5 I- I 35c & $14(13.2)$ & $27(\mid 4.1)$ & & $1.28(0.85-1.9)$ & \\
\hline \multicolumn{6}{|c|}{$\operatorname{BRCAI}(n=2 \mid 0)$} \\
\hline $\operatorname{Rad5I-135c}$ & $13(16.9)$ & $17(12.8)$ & 36.7 & $1.03(0.62-1.72)$ & \\
\hline \multicolumn{6}{|l|}{$\operatorname{BRCA} 2(n=86)$} \\
\hline $\operatorname{Rad} 51-135 c$ & I (3.6) & $10(17.2)$ & 45.0 & $2.09(1.04-4.18)$ & \\
\hline wt & $27(96.4)$ & $48(82.8)$ & 45.9 & 1 & 0.04 \\
\hline Noncarriers & $(n=155)$ & $(n=142)$ & & BC RR $(95 \% \mathrm{Cl})$ & \\
\hline $\operatorname{Rad} 51-135 c$ & $16(10.3)$ & $16(11.3)$ & & i & \\
\hline Wt & $139(89.7)$ & $126(88.7)$ & & $0.97(0.47-2.00)$ & 0.94 \\
\hline
\end{tabular}

${ }^{\mathrm{a}} \mathrm{BC}+$ : affected with breast cancer. ${ }^{\mathrm{b}} \mathrm{BC}-$ : unaffected with breast cancer. ${ }^{\mathrm{C}}$ Average age at breast cancer onset for individuals by RAD52-I 35 genotype. ${ }^{\mathrm{d}}$ Including one carrier of both 185delAG\&6174delT mutations. "wt: wild-type allele.

were identified in any of the study subjects. The difference in allele frequency between the two populations was not significant. However, to control for this difference, risk analyses were adjusted for origin, although the risk estimates changed very little with adjustment. The frequency of RAD51-135c carriers according to clinical presentation in $B R C A 1$ and $B R C A 2$ carriers is shown in Table 1.

A similar frequency of RAD51-135c heterozygotes was found among $\mathrm{BC}$ and unaffected $B R C A 1 / 2$ carriers (14.1 and $13.2 \%$, respectively, Table 2). Among BRCA2 carriers, 10 out of $58(17.2 \%)$ affected with $\mathrm{BC}$ had the RAD51-135c allele, compared with one out of $28(3.6 \%)$ of the unaffected carriers (OC cases included; Table 2). Frequencies in BRCA1 carriers were $12.8 \%$ (17 out of 133 ) and $16.9 \%$ (13 out of 77 ) in BC cases and unaffected cases, respectively. The estimated $\mathrm{BC}$ hazard ratio (HR) in BRCA1/2 carriers with the RAD51-135c allele (Table 2) was 1.28 (95\% C $0.85-1.90, P=0.23)$. A significant effect was found when the $B R C A 2$ carriers were analysed separately $(2.09,95 \%$ CI $1.04-4.18$, $P=0.04)$. The average age at BC onset was similar in carriers of both the $g$ and c RAD51-135 genotypes (45.0 and 45.9 years; Table 2); however, using Kaplan-Meier survival analysis, the median time to BC development was 45 years (95\% CI 36-54) in BCRA2-RAD51-135c carriers and 52 years $(95 \%$ CI $48-56)$ in the $B R C A 2-R A D 51$-wt group $\left(P^{\log \text { rank }}=0.0271, P^{\text {breaslow }}=0.05\right)$. In a logistic regression analysis, the estimated odds ratio (OR) adjusted for origin and age was 5.49 (95\%CI $0.5-58.8, P=0.163)$. In $B R C A 1$ carriers, no effect of the RAD51-135c was found (HR of $1.03,95 \%$ CI $0.62-1.72, P=0.09)$. The estimation of $R A D 51-135 \mathrm{~g} \rightarrow \mathrm{c}$ effect on OC in BRCA1/2 carriers was limited by small numbers.

No effect for the RAD51-135c allele on BC risk was found in the noncarrier case-control analysis. The frequency of $R A D 51-135 \mathrm{c}$ allele was $11.3 \%$ ( 16 out of 142 ) in BC cases and $10.3 \%$ (16 out of $155)$ in controls. The estimated relative risk (RR) for BC was 0.97 (95\% CI 0.47-2.00, $P=0.97$, Table 2).

\section{DISCUSSION}

Our study of the modifying effect of the $R A D 51-135 \mathrm{c} \rightarrow \mathrm{g}$ polymorphism confirms the findings of two previous studies. We found about a two-fold elevated BC risk among BRCA2 carriers with the RAD51-135c allele using COX proportional hazards models. In Kaplan-Meier survival analysis, the median age at BC development was significantly 7 years younger among BRCA2$R A D 51-135 \mathrm{c}$, compared with BRCA2-RAD51-wt carriers. For comparison, we also report the estimated OR by logistic regression analysis, which was also elevated in BRCA2-RAD51-135c carriers; however, this was nonsignificant. The BRCA2-RAD51-135c comprised only 11 cases rendering an unstable and nonsignificant OR using this model. In addition, since the unaffected carriers are at a substantial elevated lifetime risk for $\mathrm{BC}$, using a simple casecontrol analysis does not consider the age at onset in the affected group, as well as the length of follow-up in the yet, unaffected controls. The COX proportional hazard model takes into account the time factor, and therefore maybe more suitable for risk analyses in carriers.

Wang et al (2001) reported an odds ratio of BC of $3.2(95 \% \mathrm{CI}$ $1.4-4.0$ ) based on a population of $216 B R C A 2$ carriers, carrying the $R A D 51-135 \mathrm{c}$; it was also associated with a younger age at BC onset. The estimated HR associated with the RAD51-135c allele in a study of 67 Ashkenazi BRCA2 carriers was $4.1(P=0.07$; Levy-Lahad et al, 2001). Both studies, in agreement with our results, did not observe an effect of the RAD51 genotype in $B R C A 1$ carriers. Wang et al also found reduced OC risk of 0.40-0.66 among BRCA2 and RAD51$135 \mathrm{c}$ carriers, although this was nonsignificant. We could not estimate the associated OC risk due to small numbers. In noncarriers, no $\mathrm{BC}$ risk association was found. Interestingly, an opposite effect of reduced $\mathrm{BC}$ risk in BRCA1-5382insC carriers who also carry the $R A D 51-135 \mathrm{c}$ was recently reported $(\mathrm{OR}=0.23 ; 95 \%$ CI, 0.07-0.62; $P=0.0015$, Jakubowska et al, 2003). This study included individuals of Polish ancestry, with much larger frequency of the RAD51-135c allele (17 and 37\% in affected and unaffected, respectively) compared to ours and previously reported studies. The number of BRCA1-5382insC carriers in our study was too small for separate analysis. However, if these results are confirmed in additional and larger studies, the RAD51 is the first modifier gene with opposite effects in $B R C A 1$ compared in $B R C A 2$ mutation carriers.

The biological effect of the $R A D 51-135 \mathrm{~g} \rightarrow \mathrm{c}$ SNP is currently unknown; however, since a similar modifying effect has been seen in three separate studies, it is likely that it is a real risk modifier in $B R C A 2$ carriers. The BRCA2 has a distal role in DNA repair machinery (Davies et al, 2001). It directly interacts with the RAD51 protein through the BRC repeat domain and regulates the formation of RAD51 nucleoprotein filaments, which are essential for DNA repair through homologous recombination. However, the direct function of BRCA1 in DSB repair is less clear, a more proximal role in sensing and regulation of cellular response to DNA damage has been suggested by several recent papers (reviewed by Venkitaraman, 2002). The BRCA1-RAD51 complex 
contains no more than $2-5 \%$ of the cellular content of each molecule (Scully et al, 1997). Therefore, it is biologically plausible that the effect of RAD51 SNP is different in BRCA2 compared with $B R C A 1$ mutation carriers, although the biochemical mechanism remains to be determined.

Recently, the role of CHEK2, also part of the same pathway of the double-strand DNA break repair machinery, was studied in BC patients. The CHEK2 $1100^{*} \mathrm{delC}$, a truncating variant that impairs the kinase activity of the protein, is associated with an increase of $\mathrm{BC}$ risk in BRCA1/2-negative individuals with a family history (The CHEK2-Breast Cancer Consortium., 2002; Vahteristo et al, 2002). This variant conferred no increased cancer risk among BRCA1/2 carriers or sporadic cases (The CHEK2-Breast Cancer Consortium., 2002). The authors suggest that the lack of effect in $B R C A 1 / 2$ carriers is because these genes are part of the same pathway, which is already nonfunctioning in BRCA1 or BRCA2 null cells. This contradicts our finding of a modifying effect associated with the $R A D 51-135 c$ variant. Several possible reasons may account for this controversy. Impaired function of some but not all the additional proteins in a common pathway may be critical to carcinogenesis before the loss of function of the wild-type BRCA1/BRCA2 allele, while there is still a functioning BRCA1/BRCA2 protein. Alternatively, the type of genetic alteration may be important, for example, a truncating mutation $v s$ a modifying polymorphism. In the case of the 6174delT mutation, which comprises the majority of our BRCA2 carrier population as well as in the two beforementioned studies, part of the BRC repeat domains is still present. Altered function of the RAD51 protein may affect the RAD51-
BRCA2 $2^{6174 d \text { delT }}$ complex and sequester targets of action and further impair the function of the other wild-type (wt) allele as well. However, a truncated protein as in the case of the $1100^{\star}$ delC variant may either allow the other wt protein a normal function that results in a low effect on the phenotype of a BRCA1/2 mutant, or as has been previously suggested, after the loss of the wt BRCA2 allele, an additional truncated protein would have no effect. Only elucidating the biological basis of the $R A D 51-135 \mathrm{~g} \rightarrow \mathrm{c}$ polymorphism can provide answers to this controversy.

In the present study, we have reported a modifying effect for the $R A D 51-135 \mathrm{~g} \rightarrow \mathrm{c}$ SNP in BRCA2 carriers, similar to the effect reported in two previous studies. This is the first modifier gene identified in BRCA2 carriers. The clinical implication of these findings is still limited; however, it hints at differences in molecular mechanisms involved in tumour development in BRCA1 and BRCA2 carriers. The study of polymorphisms in other DNA repair genes could further elucidate the mechanism of tumorigenesis in BRCA1 and BRCA2 carriers.

\section{ACKNOWLEDGEMENTS}

LK was supported by Barclay fellowship through the British Council, for which we are most grateful. We thank the Radlett Synagogue Community for its tremendous support to this study. FD was supported by a Burroughs Wellcome Fellowship. ZKJ was supported by a legacy from the late Marion Silcock. This work is supported by the Institue of Cancer Research, UK.

\section{REFERENCES}

Davies AA, Masson JY, McIlwraith MJ, Stasiak AZ, Stasiak A, Venkitaraman AR, West SC (2001) Mol Cell 7: 273-282

Easton DF, Ford D, Bishop DT (1995) Breast Cancer Linkage Consortium. Breast and ovarian cancer incidence in BRCA1 mutation carriers. Am J Hum Genet 56: 265-271

Ford D, Easton DF, Stratton MR, Narod S, Goldgar D, Devilee P, Bishop DT, Weber B, Lenoir G, Chang-Claude J, Sobol H, Teare MD, Struewing J, Arason A, Scherneck S, Peto J, Rebbeck TR, Tonin P, Neuhausen S, Barkardottir R, Eyfjord J, Lynch $H$, Ponder BA, Gayther SA, Zelada-Hedman M, The breast cancer linkage consortium (1998) Genetic heterogeneity and penetrance analysis of BRCA1 and BRCA2 genes in breast cancer families. Am J Hum Genet 62: $676-689$

Jakubowska A, Narod SA, Goldgar DE, Mierzejewski M, Masojc B, Nej K, Huzarska J, Byrski T, Gorski B, Lubinski J (2003) Breast cancer risk reduction associated with the RAD51 polymorphism among carriers of the BRCA1 5382insC mutation in Poland. Cancer Epidemiol Biomarkers Prev 12: $457-459$

Kadouri L, Easton DF, Edwards S, Hubert A, Kote-Jarai Z, Glaser B, Durocher F, Abeliovich D, Peretz T, Eeles RA (2001) CAG and GGC polymorphisms in the anodrogen receptor gene and breast cancer risk susceptibility in BRCA1/2 carriers and non-carriers. $\mathrm{Br} J$ Cancer 85: $36-40$

Kuschel B, Auranen A, McBride S, Novik KL, Antoniou A, Lipscoml JM, Day NE, Easton DF, Ponder BA, Pharoah PD, Dunning A (2002) Variants in DNA double-strand break repair genes and breast cancer susceptibility. Hum Mol Genet 11: 1399-1407

Levy-Lahad E, Lahad A, Eisenberg S, Dagan E, Paperana T, Kasinetz L, Catane R, Kaufman B, Beller U, Renbaum P, Gershoni-Baruch R (2001) A single nucleotide polymorphism in the RAD51 gene modifies cancer risk in BRCA2 but not BRCA1 carriers. Proc Natl Acad Sci USA 98: $3232-3236$
Rebbeck TR, Kantoff PW, Krithivas K, Neuhausen S, Blackwood MA, Godwin AK, Daly MB, Narod SA, Garber JE, Lynch HT, Weber BL, Brown M (1999) Modification of BRCA1-associated breast cancer risk by polymorphic androgen-receptor CAG repeat. Am J Hum Genet 64: 1371 1377

Scully R, Chen J, Plug A, Xiao Y, Weaver D, Feunteun J, Ashley T, Livingston DM (1997) Association of BRCA1 with RAD51 in mitotic and meiotic cells. Cell 88: $265-275$

Struewing JP, Hartge P, Wacholdes S, Baker SM, Berlin M, McAdams M, Timmerman MM, Brody LC, Tucker MA (1997) The risk of cancer associated with specific mutations of BRCA1 and BRCA2 among Ashkenazi Jews. New Engl J Med 336: $1401-1408$

The CHEK2-Breast Cancer Consortium (2002) Low penetrance susceptibility to breast cancer due to CHEK $2^{*} 1100$ delC in noncarriers of BRCA1 or BRCA2 mutations. Nat Genet 31: 55-59

Thorlacius S, Struewing JP, Hartge P, Olafsdottir GH, Sigvaldason H, Tryggvadottir L, Wacholder S, Tulinius H, Eyfjord JE (1998) Populationbased study of risk of breast cancer in carriers of BRCA2 mutations. Lancet 352: $1337-1339$

Vahteristo P, Barkova J, Eerola H, Syrjakoski K, Ojala S, Kilpivaar O, Tamminen A, Kononen J, Aittomaki K, Heikkila P, Holli K, Blomquist C, Bartek J, Kallioniem OP, Nevanlinna H (2002) A CHEK2 genetic variant contributing to a substantial fraction of familial breast cancer. Am J Hum Genet 71(2): $432-438$

Venkitaraman AR (2002) Cancer susceptibility and the function of BRCA1 and BRCA2. Cell 108: $171-182$

Wang W, Spurdle AB, Kolachana P, Bove B, Modan B, Ebbers SM, Suthers G, Tucker MA, Kaufman DJ, Doody MM, Tarone RE, Daly M, Levavi H, Pierce H, Chetrit A, Yechezkel GH, Chenevix-Trench G, Offit K, Godwin AK, Struewing JP (2001) A single nucleotide polymorphism in the $5^{\prime}$ untranslated region of RAD51 risk of cancer among BRCA1/2 mutation carriers. Cancer Epidemiol Biomarkers Prev 10: 421 